\section{Estroff, Liu, Nielsch, and Wada to chair 2012 MRS Spring Meeting}

$\mathbf{M}$ eeting Chairs for the $2012 \mathrm{Ma}$ terials Research Society (MRS) Spring Meeting are Lara A. Estroff(Cornell University), Jun Liu (Pacific North-

\section{MRS} west National Laboratory), Kornelius Nielsch (University of Hamburg), and Kazumi Wada (University of Tokyo). The meeting will be held in San Francisco on April 9-13.

Lara A. Estroff is an assistant professor of Materials Science and Engineering at Cornell University. Her research group focuses on bio-inspired materials synthesis, in particular, the study of crystal growth mechanisms in gels and their relationships to biomineralization. Estroff received a BA degree from Swarthmore

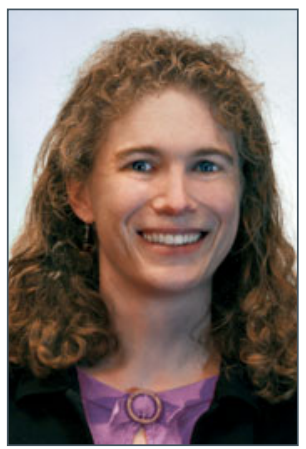

College (1997), with a major in chemistry and a minor in anthropology. Before beginning her graduate studies, she spent a year at the Weizmann Institute of Science in Rehovot, Israel as a visiting researcher where she was introduced to the field of biomineralization and studied chemical approaches to archeological problems. In 2003, she received her PhD degree in chemistry from Yale University. Afterwards, she was an NIH-funded postdoctoral fellow at Harvard University (2003-2005). Estroff has received several awards, including an NSF Early Faculty Career Award in 2009 and a J.D. Watson Young Investigator's award from NYSTAR in 2006.

Jun Liu is a Laboratory Fellow at the Pacific Northwest National Laboratory (PNNL) where he leads the Transformational Materials Science Initiative. He is

recognized for his research in functional nanomaterials and their application for energy and the environment, in particular in the area of solution synthesis and

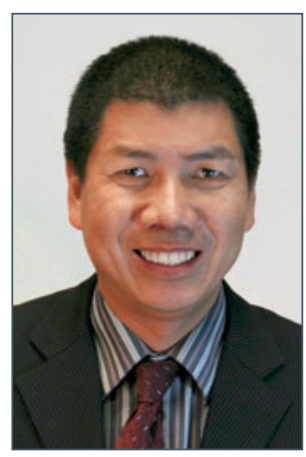
crystallization, self-assembly, environmental clean-up, catalysis, and largescale energy storage. He has over 200 publications and many invited review articles in leading journals. Liu previously served as technical staff member at the Pacific Northwest National Laboratory, Sandia National Laboratories, and Lucent Bell Labs. He also served as Department Manager for the Chemical Synthesis and Nanomaterials Department and as Thrust Leader for Complex Functional Nanomaterials for the Center for Integrated Nanotechnologies (CINT), both at Sandia National Laboratories. Liu's honors include an R\&D 100 Award for self-assembled nanoporous materials, and the 2007 Distinguished Inventor of Battelle.

Kornelius Nielsch is Professor of Experimental Physics at the Institute of

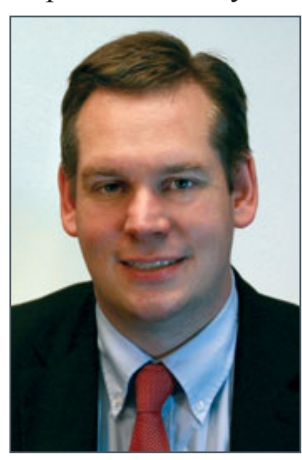

Applied Physics of the University of Hamburg, Germany and coordinator of the German Priority Program of Thermoelectric Nanostructures, funded by the German Science Foundation (DFG). His research focuses on nanostructured thermoelectric and magnetic model systems. In the field of oxide and semiconductor materials, his group has a strong emphasis on atomic layer deposition. Nielsch studied physics at the Mercator University in Duisburg (1993-1997) and conducted his diploma work at the University of Lund, Sweden. His doctoral thesis was carried out at the Max-Planck-Institute of Microstructure Physics in Halle, Germany. In 2002 he worked as a postdoctoral associate at the Massachusetts Institute of Technology. From 2003 to 2008, he was the leader of a nanotechnology research group funded by the German Federal Ministry of Education and Research (BMBF) on multifunctional nanowires and nanotubes at the Max-Planck-Institute in Halle. He has co-authored more than 95 articles and three patents. In 2006, the State of Saxony-Anhalt awarded Nielsch the State Research Prize for Basic Research.

Kazumi Wada is a Professor of Microphotonics, Materials Engineering, at the University of Tokyo. His research focus includes on-chip light emitters and optical data processing. He received his $\mathrm{PhD}$ degree in instrumentation engineering from Keio University, Yokohama, Japan. Since joining Research Labo-

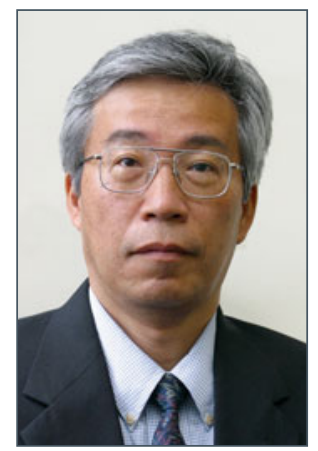
ratories, Nippon Telephone and Telegraph (NTT) in Tokyo in 1975, Wada was engaged in research of $\mathrm{Si}$ and III-V materials and devices. Since 1998, he was with the Microphotonics Center and with the Department of Materials Science and Engineering at the Massachusetts Institute of Technology, conducting research on Si photonics. He returned to Japan in 2004 to accept a professorship at the University of Tokyo, managing his microphotonics laboratory for Si photonics research. He has authored and coauthored more than 100 articles and has edited 13 books. Among his honors and services, Wada is a fellow of the Japan Society of Applied Physics. 